\title{
BMJ Open Prospective observational study protocol to investigate long-term adverse effects of methylphenidate in children and adolescents with ADHD: the Attention Deficit Hyperactivity Disorder Drugs Use Chronic Effects (ADDUCE) study
}

\author{
S K Inglis, ${ }^{1}$ S Carucci, ${ }^{2}$ P Garas, ${ }^{3}$ A Häge, ${ }^{4}$ T Banaschewski, ${ }^{4} \mathrm{~J}$ K Buitelaar, ${ }^{5}$ \\ R W Dittmann, ${ }^{4} \mathrm{~B}$ Falissard, ${ }^{6} \mathrm{C}$ Hollis, ${ }^{7} \mathrm{H}$ Kovshoff, ${ }^{8} \mathrm{E}$ Liddle, ${ }^{7} \mathrm{~S}$ McCarthy, ${ }^{9}$ \\ P Nagy, ${ }^{3}$ A Neubert, ${ }^{10}$ E Rosenthal, ${ }^{11}$ E Sonuga-Barke, ${ }^{12}$ I Wong, ${ }^{13}$ A Zuddas, ${ }^{2}$ \\ D C Coghill, ${ }^{14}$ and the ADDUCE Consortium
}

To cite: Inglis SK, Carucci S, Garas P, et al. Prospective observational study protocol to investigate long-term adverse effects of methylphenidate in children and adolescents with ADHD: the Attention Deficit Hyperactivity Disorder Drugs Use Chronic Effects (ADDUCE) study. BMJ Open 2016;6:e010433.

doi:10.1136/bmjopen-2015010433

- Prepublication history for this paper is available online. To view these files please visit the journal online (http://dx.doi.org/10.1136/ bmjopen-2015-010433).

Received 2 November 2015 Revised 29 January 2016 Accepted 18 March 2016

CrossMark

For numbered affiliations see end of article.

Correspondence to

SK Inglis;

s.k.inglis@dundee.ac.uk

\section{ABSTRACT}

Introduction: Methylphenidate is the most frequently used medication for the treatment of attention-deficit/ hyperactivity disorder (ADHD) in Europe. Following concerns about its safety, the European Commission called for research into the long-term effects of methylphenidate on children and adolescents with ADHD. The Attention Deficit Hyperactivity Disorder Drugs Use Chronic Effects (ADDUCE) research programme was designed to address this call. At the heart of this programme is a 2-year longitudinal naturalistic pharmacovigilance study being conducted in 27 European sites.

Methods and analysis: 3 cohorts of children and adolescents (aged 6-17) living in the UK, Germany, Italy and Hungary are being recruited:

Group 1 (Medicated ADHD): 800 ADHD medicationnaive children and adolescents with a clinical diagnosis of ADHD about to start methylphenidate treatment for the first time.

Group 2 (Unmedicated ADHD): 400 children and adolescents with a clinical diagnosis of ADHD who have never been treated with ADHD medication and have no intention of beginning medication.

Group 3 (Non-ADHD): 400 children and adolescents without $A D H D$ who are siblings of individuals in either group 1 or 2.

All participants will be assessed 5 times during their 2year follow-up period for growth and development, psychiatric, neurological and cardiovascular health. The primary outcome measure will be the height velocity SD score.

Ethics and dissemination: Ethical approval for the study has been granted by the East of Scotland Research Ethics Service. Following this approval, patient information leaflets and consent forms were translated as necessary and submissions made by lead sites in each of the other 3 countries to their own

\section{Strengths and limitations of this study}

- The Attention Deficit Hyperactivity Disorder Drugs Use Chronic Effects (ADDUCE) will provide longterm pharmacovigilance data about methylphenidate use in children and adolescents with attentiondeficit/hyperactivity disorder (ADHD).

- In particular, the study will provide information about the effects of methylphenidate on growth and development, psychiatric health, neurological health, cardiovascular function.

- The study includes two control groups: one of children and adolescents with ADHD who are unmedicated, and one of children and adolescents without ADHD.

- Owing to its naturalistic design, participants are not randomised to a particular group and there is no placebo-control group in the design.

- The number and type of assessments that we wished to conduct has to be balanced against the time burden placed on our participants. Therefore, while it would have been desirable to collect data on cognitive testing, acceptability of the medication and quality of life, we were unable to fit these tests into our assessment schedule.

- Although the European Union agreed that the 2-year follow-up described in this study fulfilled their requirement for an investigation of the 'long-term' effects of methylphenidate, many children and adolescents are prescribed the drug for longer than this. If future funding is secured, consent may be sought from some or all participants for additional, longer term follow-up.

ethics committees. Following ethical approval in each country, local ethical permissions at each site were sought and obtained as needed. The study's website 
(http://www.adhd-adduce.org/page/view/2/Home) provides information for researchers, participants and the general public.

Trial registration number: NCT01470261.

\section{INTRODUCTION}

Attention-deficit/hyperactivity disorder (ADHD) is a neurodevelopmental disorder characterised by core symptoms of inattention, hyperactivity and impulsivity. ${ }^{1}$ The worldwide prevalence is estimated at $5.3 \%$ with a prevalence for children around $6.5 \%$ and $2.7 \%$ for adolescents with no significant differences between Northern America and Europe. ${ }^{2}$

The most commonly prescribed medication for the treatment of ADHD in children and adolescents is methylphenidate (MPH), a central nervous system psychostimulant medication. ${ }^{3} 4$

The mechanism of action of psychostimulants is not completely clear; however, it is believed that they inhibit the reuptake of dopamine and norepinephrine into the presynaptic neuron and/or increase their release into extraneuronal space, thus increasing intrasynaptic concentrations. ${ }^{5}$ Randomised controlled trials of MPH have established its efficacy with around $70 \%$ of patients responding positively, with improvements seen in many areas including inattentiveness, impulsiveness, hyperactivity and self-esteem. ${ }^{6}$

MPH has been available in the European Union (EU) since the $1950 \mathrm{~s}$, and its use has increased markedly in Western countries over the past decade. In England and Wales, prescriptions for MPH rose to over 650000 in 2012, a $56 \%$ rise since $2007,{ }^{7}$ and a similar pattern of growth in prescriptions has been evident in other European countries such as Germany, Sweden, Switzerland and Spain, ${ }^{8-11}$ the $\mathrm{USA}^{12}$ and Asia. ${ }^{13}$ Perhaps surprisingly for a drug so widely prescribed, the adverse effect profile of the drug is not fully characterised. This is partly because the regulatory requirements for such information at the time the drug was licensed were less stringent than those currently in place. Much of the clinical research in this area has focused on short-term efficacy with trial designs often limited by short experimental duration, small numbers of patients and inappropriate control groups. This has resulted in data sets with limited information on drug tolerability and safety. Some of the data obtained by these studies, together with spontaneous reports of adverse events by marketing authorisation holders, raised sufficient concern over the safety of MPH that the European Commission requested a community referral to its Committee for Medicinal Products for Human Use (CHMP) for all MPH-containing products in June $2007 .{ }^{14}$ Such referrals are initiated when there are concerns relating to the protection of public health or where other community interests are at stake. ${ }^{15}$ The CHMP concluded in January 2009 that overall the benefit of MPH outweighs the risk when prescribed to children with ADHD aged 6 years and over. ${ }^{16}$ However, the Committee made recommendations to standardise prescribing and provision of safety information across all EU member states. Importantly, the report also stated that more data are required on the long-term effects of MPH on children and adolescents and concluded that further research should be carried out to investigate long-term effects of MPH on (1) growth and development, (2) neurological health, (3) psychiatric health, (4) sexual development and fertility and (5) cardiovascular effects in adults who have taken/are taking MPH. ${ }^{16}$ The CHMP emphasised the need for designs that allow the comparison of exposed children with suitable control groups bearing in mind that ADHD covers a broad spectrum of behaviour and may be associated with other disorders. As a result of these recommendations for further research, the Fourth Call of the European Commission's Framework Programme (FP7) invited proposals addressing the 'long-term effects in children and in young adults of $\mathrm{MPH}$ in the treatment of ADHD'. ${ }^{17}$

To answer this call, the Attention Deficit Hyperactivity Disorder Drugs Use Chronic Effects (ADDUCE) consortium was established, comprising experts in the fields of ADHD, drug safety, neuropsychopharmacology and cardiovascular research. It developed a programme of research designed to fill the identified gaps in the current literature and to address the concerns of CHMP, and it was funded in 2012.

The ADDUCE programme has a number of empirical work packages (WPs). ${ }^{18}$ This paper focuses on the work of WP 3, which is a 2-year prospective cohort study with appropriate control groups that forms part of the ADDUCE project and is designed to provide new data to specifically answer the questions raised by CHMP about long-term MPH safety in children and adolescents with ADHD. This study is underway and data collection will be completed in January 2016.

\section{METHODS AND ANALYSIS \\ Objectives}

ADDUCE WP 3 addresses scientific questions about prevalence, clinical significance, development and moderating and/or mediating factors of four specific classes of potential long-term adverse effects of MPH on growth, neurological, psychiatric and cardiovascular health.

Evidence from observational studies providing longitudinal data indicates that treatment with MPH may result in a reduction in the rate of growth, ${ }^{19-23}$ in particular during the first year of treatment. ${ }^{20}$ There remain uncertainties over whether any changes in height persist in the long term, and whether changes are the result of medication or whether ADHD itself is associated with growth problems. In view of these uncertainties and the clear importance of determining whether MPH treatment does have effects on growth, the height velocity SD score (SDS) was chosen as the primary outcome measure. 
While the height velocity SDS was chosen as the primary outcome measure on which to base the sample size, the study will collect data on other key outcomes in the fields of growth, cardiovascular system, psychiatric and neurological health. MPH acts primarily as a dopaminenorepinephrine reuptake inhibitor by binding to and blocking dopamine transporters ${ }^{24}$ and increased levels of norepinephrine and dopamine can potentially affect the cardiovascular system such as heart rate ${ }^{25}$ and the central nervous system (CNS) system such as psychosis. ${ }^{26}$ The effectiveness of MPH medication will also be assessed.

\section{Study design}

Design

The study is a 2-year naturalistic longitudinal prospective pharmacovigilance multicentre study investigating the long-term tolerability and safety of MPH in children and adolescents aged between 6 and 17 years.

\section{Cohorts}

Three cohorts of children and adolescents (aged 6-17) are being recruited from child and adolescent mental health services in the UK, Germany, Italy and Hungary:

Group 1 (Medicated ADHD): comprises children and adolescents with a clinical diagnosis of ADHD according to Diagnostic and Statistical Manual of Mental Disorders, Fourth Edition (DSM IV) criteria who have not yet been medicated with any ADHD medication and are about to start MPH treatment for the first time. Group 2 (Unmedicated ADHD): comprises children and adolescents with a clinical diagnosis of ADHD according to DSM IV criteria who have never been treated with ADHD medication and for whom there is no current intention of beginning treatment with ADHD medication.

Group 3 (Non-ADHD): comprises children and adolescents without ADHD who are siblings of individuals in either group 1 or 2.

\section{Eligibility criteria}

The inclusion criteria are deliberately broad and the exclusion criteria minimal. This is to ensure that the study captures a typical group of patients with ADHD presenting to clinical services throughout the EU and that the results are applicable across Europe.

Participants eligible for group 1 or 2 must be diagnosed as having ADHD according to DSM IV criteria by a qualified clinician according to normal clinical practice in each country. The diagnosis may take into account reports from schools and carers.

Participants in group 3 must score less than 1.5 on the Swanson Nolan and Pelham IV Rating scale (SNAP IV ${ }^{27}$ ) for the ADHD items. Their hyperactivity score on the parent-rated Strength and Difficulties Questionnaire $\left(\mathrm{SDQ}^{28}\right)$, should be within the normal range for their country (eg, $<6$ for the UK). Full biological siblings are preferred for this group, although half-siblings and siblings not biologically related to the proband will also be considered. A strict order of preference is defined so that older siblings of the same sex as the proband have the highest preference, followed by younger siblings of the same sex, older siblings of the opposite sex and finally younger siblings of the opposite sex.

Participants are eligible if they are taking other psychotropic drugs. A medication history is collected at each study visit.

\section{Enrolment}

Participants eligible for groups 1 and 2 are identified by the principal investigator or a designee who is experienced in the evaluation of children and adolescents with ADHD. Age-appropriate information about the study is provided to the child/adolescent and parent/legal guardian. If the participant is eligible and willing, a researcher who has received Good Clinical Practice (GCP) and consent training takes informed written consent from the parent/legal guardian and assent from the participant. Participants aged 16 or 17 years may provide their own written consent, depending on the regulations of the country in which they are recruited. The right of a child or parent to refuse to participate is respected. Participants are free to withdraw at any time during the study, and this will not influence their clinical treatment. If a participant withdraws during the assessment period, data collected up until the point of withdrawal will remain in the study database and be included in the final analysis.

Siblings of participants enrolled into groups 1 and 2 are invited to participate in the study in group 3 and given age-appropriate study information. If they are willing to participate, they are asked to give written consent/assent as for groups 1 and 2 and, if they meet the eligibility criteria, are enrolled into the study.

\section{Outcome measures}

The study outcomes are aligned with the categories highlighted by CHMP as requiring more research; growth, cardiovascular system, psychiatric and neurological health ${ }^{16}$ together with effectiveness of MPH treatment (table 1).

Height velocity, the primary outcome measure on which the sample size was calculated, was operationalised as height velocity SDS, ${ }^{29}$ defined as height velocity, $v$, estimated from at least two consecutive measurements, and normalised with reference to the mean and SD of a population of the same age and sex:

$$
\frac{\text { height velocity } \operatorname{SDS}=\mathrm{v}-\overline{\mathrm{v}}}{\mathrm{SD}}
$$

The mean and SD height velocities for each country represented in the study will be obtained from the most recent charts available for each country.

\section{Sample size calculation}

A variation in instantaneous height velocity SDS of 0.25 is equivalent to a reduction in height velocity of around $0.5 \mathrm{~cm} /$ year. $^{29}{ }^{30} \mathrm{In}$ a sample of 600 treated patients and 300 untreated patients, such a variation can be detected 
Table 1 Outcome measures

\begin{tabular}{|c|c|c|}
\hline Category & Assessment tool & Outcomes \\
\hline \multirow[t]{9}{*}{$\begin{array}{l}\text { Growth and } \\
\text { development }\end{array}$} & Height measure $^{32}$ & $\begin{array}{l}\text { Proportion with height below } 2 \text { nd centile } \\
\text { Proportion with height below } 0.4 \text { th centile }\end{array}$ \\
\hline & Weight measure $^{32}$ & Weight \\
\hline & & Proportion with weight below 2nd centile \\
\hline & & Proportion with weight below 0.4 th centile \\
\hline & Calculated BMI & BMI \\
\hline & & Proportion with BMI below 2nd centile \\
\hline & & Proportion with BMI below 0.4 th centile \\
\hline & Tanner pubertal staging ${ }^{33} 34$ & Pubertal stage \\
\hline & Hand X-ray & Bone age (substudy) \\
\hline \multirow[t]{3}{*}{ Cardiovascular system } & Heart rate ${ }^{32}$ & Proportion with heart rate above $120 \mathrm{bpm}$ \\
\hline & Diastolic blood pressure 32 & Proportion with diastolic blood pressure above $90 \mathrm{~mm} \mathrm{Hg}$ \\
\hline & Systolic blood pressure ${ }^{32}$ & Proportion with systolic blood pressure above 95th centile \\
\hline \multirow[t]{20}{*}{ Psychiatric } & $\mathrm{MFQ}^{39}$ & Assessment of depression. \\
\hline & & Total score and proportion above clinical cut-off \\
\hline & $\mathrm{PLikS}^{40}$ & Assessment of delusions and hallucinations. \\
\hline & & Proportion with definite PLikS and proportion with suspected PLikS \\
\hline & DAWBA modules ${ }^{41}$ & Rapidly changing mood. Proportion above cut-off \\
\hline & & Tics section. Proportion above cut-off \\
\hline & & Awkward and troublesome behaviour. \\
\hline & & Proportion above cut-off \\
\hline & YGTSS $^{42}$ & Proportion reporting motor tics \\
\hline & & Proportion reporting phonic tics \\
\hline & C-SSRS ${ }^{63}$ & Proportion reporting any suicidal ideation \\
\hline & & Proportion reporting any suicidal behaviour \\
\hline & & Proportion reporting each type of behaviour \\
\hline & & Number of suicidal behaviours \\
\hline & & Lethality of suicidal behaviours \\
\hline & & Proportion reporting each type of suicidal ideation \\
\hline & & Suicidal ideations severity rating \\
\hline & & Suicidal ideation intensity rating \\
\hline & $S U Q^{43}$ & Proportion with any substance use \\
\hline & & $\begin{array}{l}\text { Proportion with use of specific substances; nicotine, } \\
\text { alcohol, cannabis, other drugs }\end{array}$ \\
\hline \multirow[t]{3}{*}{ Neurological } & $\mathrm{CSHQ}^{45}$ & Total score and subscores; proportion above cut-offs \\
\hline & AIMS $^{44}$ & Total score. \\
\hline & & Question 8 score \\
\hline \multirow[t]{6}{*}{ Treatment effectiveness } & SNAP-IV ${ }^{27}$ & Clinically significant change defined as SNAP total ADHD score $\leq 27$ \\
\hline & $\mathrm{CGI}^{35}$ & $\begin{array}{l}\text { Global evaluation of severity of symptoms and improvement over } \\
\text { time }\end{array}$ \\
\hline & CGAS $^{36}$ & $\begin{array}{l}\text { Global evaluation of severity of symptoms and improvement over } \\
\text { time }\end{array}$ \\
\hline & $\mathrm{SDQ}^{28}$ & $\begin{array}{l}\text { Behavioural screen of emotional symptoms, conduct problems, } \\
\text { hyperactivity/inattention, peer relationship problems and prosocial } \\
\text { behaviour. Total score and proportion above clinical cut-off }\end{array}$ \\
\hline & $\mathrm{DCDQ}^{\prime} 07^{37}$ & Scores motor control, fine motor control and general coordination \\
\hline & $\mathrm{SCQ}^{38}$ & $\begin{array}{l}\text { Evaluates communication skills and social functioning in children } \\
\text { who may have autism spectrum disorders }\end{array}$ \\
\hline
\end{tabular}

ADHD, attention-deficit/hyperactivity disorder; AIMS, Abnormal Involuntary Movement Scale; BMI, body mass index; CGAS, Children's Global Assessment; CGI,Clinical Global Impressions; CSHQ, Child's Sleep Habits Questionnaire; C-SSRS, Columbia-Suicide Severity Rating Scale; DAWBA, Development and Wellbeing Assessment; DCDQ'07, Developmental Coordination Disorder Questionnaire '07; MFQ, Mood and Feelings Questionnaire; PLikS, Psychosis Like Symptoms; SCQ, Social Communication Questionnaire; SDQ, Strength and Difficulties Questionnaire; SNAP-IV, Swanson Nolan and Pelham IV rating scale; SUQ, Substance Use Questionnaire; YGTSS, Yale Global Tic Severity Scale.

with a power of $94 \%$ (type 1 error=0.05). Further power calculations for the secondary outcomes confirmed that 600 medicated patients with ADHD (group 1) and 300 non-medicated patients with ADHD (group 2) will produce sufficient power to determine the adverse effects of MPH. 
To calculate the sample size needed for each group, the likely attrition rate due to dropouts over the 24-month follow-up period was anticipated to be around $25 \%$ based on experience from a previous longitudinal study of a similar population (ADORE study, ${ }^{31}$ personal communication D. Coghill). Thus, the target size is 800 for group 1, 400 for group 2 and 400 for group 3.

Recruitment targets are divided among the four countries so that each country is required to recruit 200 to group 1 and 100 to group 3. Since the population of unmedicated children with ADHD is much larger in Italy and Hungary compared with that in the UK and Germany, Italy and Hungary are required to recruit 200 children each to group 2, with the UK and Germany having no target for this group.

\section{Assessment tools}

The assessment tools were chosen to provide outcome measures in each of the four topic areas identified by CHMP as requiring new information, ${ }^{16}$ together with outcomes describing the effectiveness of MPH medication. Details of the assessment tools and the outcomes associated with each tool are given in table 1. A brief description is given below.

1. Growth and development: Height and weight will be measured following the standard operating procedures developed by the Scottish Children's Research Network. ${ }^{32}$ Standardised measures of growth parameters at each time point will be calculated according to the best available country-specific norms. Pubertal maturation will be assessed using the Tanner scale. ${ }^{33}{ }^{34}$ In a subgroup of 70 medicated Italian participants with ADHD, pubertal staging will be performed by an expert paediatrician endocrinologist by using Tanner staging of breast development and pubic hair and by physical examination of testicle volume using Prader's orchidometer. The same patients will undergo an X-ray of the left hand and wrist for determination of age. Bone age is determined by comparing each of 20 bonds of an X-ray of the left hand with the Tanner and Whitehouse atlas, giving a score to each one and then calculating an 'age' from the score of the 20 bones from long bones (see section Substudy below for additional details). An assessment of intellectual function will be made at baseline by determining whether and to what extent the child receives extra help at school.

2. Psychiatric health: The assessments chosen to assess psychiatric health are detailed in table 1. The SNAP-IV $^{27}$ will be used to measure the ADHD-related behaviours of participants. The Clinical Global Impressions $\left(\mathrm{CGI}^{35}\right)$ and Children's Global Assessment Scales $\left(\right.$ CGAS $^{36}$ ) will be used as a secondary measure of effectiveness, in particular for ADHD symptoms. The SDQ is a brief behavioural screening questionnaire for mental health problems in children and adolescents aged $3-16$ years, ${ }^{28}$ while the Developmental Coordination Disorder Questionnaire (the DCDQ'07) is a brief parent questionnaire designed to screen for coordination disorders in children aged 5-15 years. ${ }^{37}$ We will also use the Social Communication Questionnaire (SCQ), which is a brief parent-rated instrument designed to evaluate communication skills and social functioning in children who may have autism or autism spectrum disorders $^{38}$ and the Mood and Feelings Questionnaire (MFQ) Short Version to assess depressive symptoms. ${ }^{39}$ The Psychosis Like Symptoms (PLikS) is a semistructured instrument that draws on the principles of the Present State Examination. ${ }^{40}$ We will be using an abbreviated version with items relating to hallucinations and delusions since these are the most common psychotic symptoms. Modules from the Developmental and Wellbeing Assessment (DAWBA) package will be used to screen for the presence of tics and to rate emotional lability. ${ }^{41}$ If the DAWBA tics screen is positive, the Yale Global Tic Severity Scale (YGTSS) will be used to describe the severity of the tics and the level of impairment they impart. ${ }^{42}$ Suicidal ideation and behaviour will be measured using the Columbia-Suicide Severity Rating Scale (C-SSRS, Kelly Posner, personal communication), which is the instrument recommended by the Food and Drugs Administration (FDA) in child and adolescent clinical trials. Any substance misuse will be assessed using the Substance Use Questionnaire (SUQ), developed for use in the Multimodal Treatment study of children with ADHD (MTA). ${ }^{43}$

3. Neurological health: Two tools will be used to assess neurological health: the Abnormal Involuntary Movement Scale (AIMS) to measure dyskinesias ${ }^{44}$ and the Child's Sleep Habits Questionnaire (CSHQ) to assess sleep difficulties. ${ }^{45}$

4. Cardiovascular health: To assess cardiovascular health, blood pressure will be measured at each visit following the standard operating procedure developed by the Scottish Children's Research Network ${ }^{32}$ and recorded as age-adjusted and height-adjusted centiles. ${ }^{46} \mathrm{~A}$ brief cardiac examination will also be performed by a clinician at the first study visit (table 2). A more detailed study of the effects of long-term use of MPH on cardiovascular health in a separate cohort of children and adolescents will also be carried out by the ADDUCE consortium. This separate study will be described elsewhere.

5. Effectiveness: The effectiveness of MPH treatment will be assessed using the tools described in table 1.

Together with these assessments, demographic data and information about the medical and psychiatric histories of the participant and their relatives will be collected (table 3).

\section{Assessment schedule}

Participants in all three groups will undergo the same assessments, at six-monthly intervals for 2 years, so that 
Table 2 Cardiac examination

Inspection

Look at the participant

Look at the hands

Feel the radial pulse

\section{Palpation}

Feel for the apex beat

Auscultation

Simultaneously listen and palpate a pulse (preferably a central pulse) to time any murmur to the cardiac cycle

Listen over the apex beat (mitral area) with the bell, and then the diaphragm

Listen over the left sternal edge in the 4th intercostal space (tricuspid area)

Listen over the left sternal edge in the 2nd intercostal

space (pulmonary area)

Listen over the right sternal edge in the 2nd intercostal Listen for heart sounds 1 and 2, systolic and diastolic murmurs space

Measure blood pressure

A brief cardiac examination will be conducted to include.
Comfortable at rest, cyanosis, breathless, scars, syndromes (eg, Marfan's, Down's, Turner's)

Clubbing, peripheral cyanosis

Assess rate (over $15 \mathrm{~s}$ ) and rhythm (sinus, regularly irregular or irregularly irregular)

Usually in the 5th intercostal space in the midclavicular line.
Listen for heart sounds 1 and 2 (and 3 and 4), systolic and diastolic murmurs

Listen for heart sounds 1 and 2, systolic and diastolic murmurs

Listen for heart sounds 1 and 2, systolic and diastolic murmurs they have five study visits in total (figure 1). Participants in the medicated ADHD group (group 1) will have their first assessment before they begin MPH treatment. The study visits can be carried out during an 8-week period around the date that the visit is due, maximising the opportunity for the visit to take place. Assessments of all primary and secondary measures will be made at each study visit, with the exception of the visit at 18 months at which only the height, weight, blood pressure, vital signs and pubertal maturation will be assessed, and medication history updated (table 4 ).
Study set up

The lead country for the study is the UK, with sponsorship provided by Tayside Medical Science Centre (TASC), a joint partnership of National Health Service (NHS) Tayside and the University of Dundee. ${ }^{47}$ Patient information leaflets and consent forms were translated as necessary in each country and submissions were then made by each of the other three countries to secure ethical permission at their own sites. Overall management of the trial is being provided by the Tayside Clinical Trials Unit (TCTU), a UK Clinical

Table 3 Assessment of demographic details and family history

\begin{tabular}{ll}
\hline Demographics & Age \\
& Sex \\
& Nationality \\
& Ethnicity \\
& Siblings \\
& Marital status of parents \\
& Type of family home \\
& Birth weight \\
Personal history & Gestational age at delivery \\
& Intellectual functioning \\
& Physical health (history of syncope, head injury, seizures, genetic syndromes, cardiac problems, \\
& hypertension, diabetes, asthma or epilepsy) \\
& Psychological health (axes 1 and 2 mental disorders) \\
Medication history & Past psychiatric medications (name, dose, frequency, date started, date stopped) \\
& Current psychiatric medications (name, dose, frequency, date started) \\
& Other current medications (name, dose, frequency, date started) \\
& Allergies or sensitivity to medication \\
& Psychiatric medication started at study visit (name, dose, frequency) \\
& Reported concordance with current medications \\
& Physical health (cardiac problems, hypertension, diabetes, asthma or epilepsy) \\
& Psychological health (axes 1 and 2 mental disorders)
\end{tabular}


Figure 1 Study design flow chart.
Screening

phase (if

required)

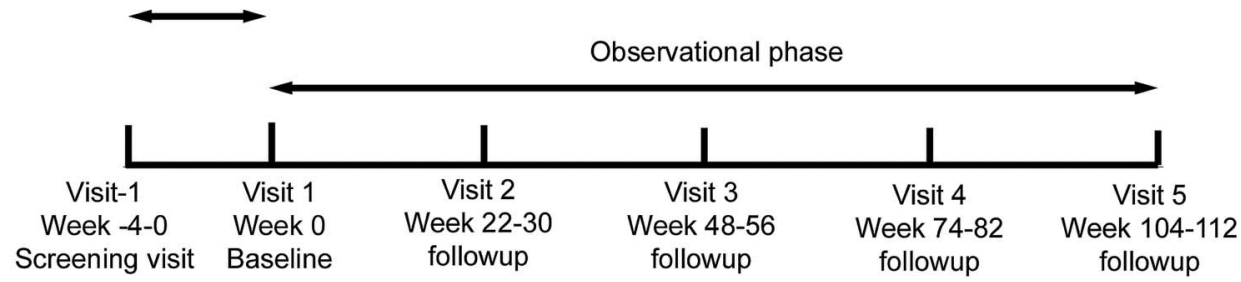

Research Collaboration (UKCRC)-registered clinical trials unit. ${ }^{47}$

Study-specific training was given to lead representatives of all sites at an initial set-up meeting. A training package was developed on the basis of that meeting and provided to all researchers working on the study.

The design of the project enables the study to be run differently in the four participating countries, within the boundaries of the study protocol. Each country has a lead site which coordinates and supports the study at the other sites within that country.

\section{Training and quality control across sites}

To ensure that the data collected from the study are of the highest quality, the ADDUCE study is being conducted to standards that accord with GCP guidelines. ${ }^{48}$ A number of measures have been put in place to ensure that the data are of high quality and are collected in a consistent way across all sites. These include a comprehensive training package which includes audio and video records of the initial training meeting and will be completed by all researchers before they begin work on the study. Additionally, training meetings have been held in each country for which there is more than one site, to ensure that information is disseminated from the lead sites to their satellite sites, and there is good communication between sites in each country. This communication will be maintained throughout the study period through regular teleconferences, emails and face-to-face meetings. Finally, the trial manager located in Dundee will oversee the work at all sites, ensuring that all sites are adhering to the research governance regulations, are collecting good-quality data and are entering those data into the electronic data management system correctly.

\section{Substudy}

As a complementary part of the present 2-year naturalistic pharmacovigilance European multicentre study, a specific substudy within the ADDUCE project will contribute to evaluate the long-term effects of MPH on growth and pubertal maturation.

Poor growth is a common concern related to stimulant medications, especially with children already on the lower growth percentiles. Studies providing longitudinal data indicate a reduction in height and weight gain; these effects are usually minimal, but there is substantial variability with some children being completely unaffected, whereas others show significant growth suppression. ${ }^{49-51}$ Early studies have suggested that final adult height is not affected by administration of psychostimulants; ${ }^{52} 53$ nevertheless, follow-up periods are often not sufficiently long enough to allow firm conclusions to be drawn and these studies do not appear to consider the effect of puberty on growing processes and were not normalised for pubertal stage.

Within the Italian medicated cohort, 70 medicated Italian patients with ADHD, aged 6-12, will be assessed by an accurate assessment of growth parameters and pubertal staging performed by an expert paediatrician endocrinologist. The monitoring of bone age will also be explored as a possible helpful tool, adding value to the routine measures of growth. Bone age is regarded as the gold standard to evaluate the 'growing power' of an individual and represents a major tool to calculate expected final height. The sample size of $\mathrm{N}=70$ has been calculated as for an exploratory study. The paucity of previous data about X-rays in this population and its cost prevented the procedure being extended to the entire sample. The number of 70 has been therefore considered sufficient to provide general information in order to evaluate the validity of this tool.

Measurements of bone age at baseline allow calculation of the expected final height using the methods of Tanner et al. ${ }^{54}$ Subsequent yearly measurements will allow calculation of the rate of bone maturation. Bone age/ chronological age ratio is related to the growth potential of a child; an increase of the ratio is negatively related to the predicted final and adult height. Therefore, a decrease in height velocity with no decrease in bone maturation rate will reduce the final expected height and may result in short stature; hence, it will represent an adverse outcome on growth. An increase in the difference (bone age-chronological age) $\geq \pm 6$ months $(+1$ SD) is deemed clinically significant, representing a change in a child's growing potential.

The radiological risk related to X-ray of the left hand is very low, equivalent to a 2-week stay at a mountain or seaside area. ${ }^{55}$ The child will not be exposed to the risk of a cumulative effect of radiation because the time interval between two radiograms is long enough.

\section{Data collection and management}

Data collected at each study visit will be entered into a paper case report form (CRF). The data will 
Table 4 Schedule of study visits and assessments

\begin{tabular}{|c|c|c|c|c|c|c|}
\hline $\begin{array}{l}\text { Visit } \\
\text { Visit schedule }\end{array}$ & $\begin{array}{l}\text { Screen } \\
\text { Week } \\
-4-0\end{array}$ & $\begin{array}{l}\text { Visit } 1 \\
\text { Baseline } \\
\text { Week } 0\end{array}$ & $\begin{array}{l}\text { Visit } 2 \\
\text { 6-month } \\
\text { Weeks } \\
\text { 22-30 }\end{array}$ & $\begin{array}{l}\text { Visit } 3 \\
\text { 12-month } \\
\text { Weeks } \\
48-56\end{array}$ & $\begin{array}{l}\text { Visit } 4 \\
\text { 18-month } \\
\text { Weeks } \\
74-82\end{array}$ & $\begin{array}{l}\text { Visit } 5 \\
\text { 24-month } \\
\text { Weeks } \\
100-108\end{array}$ \\
\hline Informed consent/assent & $\checkmark$ or & $\checkmark$ & & & & \\
\hline Inclusion/exclusion criteria & $\checkmark$ or & 2 & & & & \\
\hline Demographics & & $\checkmark$ & & & & \\
\hline Family medical and psychiatric history & & 2 & & & & \\
\hline Child medical and psychiatric history & & $\checkmark$ & & & & \\
\hline Developmental history & & $\checkmark$ & & & & \\
\hline Medication history and current medications & & $\checkmark$ & & & & \\
\hline $\begin{array}{l}\text { Psychiatric medication (s) Prescribed or } \\
\text { continued at visit (including drug and dose } \\
\text { and concordance) }\end{array}$ & & $\checkmark$ & $\checkmark$ & $\checkmark$ & $\checkmark$ & $\checkmark$ \\
\hline Other medication since last visit & & & $\checkmark$ & $\checkmark$ & $\checkmark$ & $\checkmark$ \\
\hline Learning difficulties & & 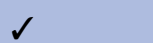 & & & & \\
\hline Cardiac examination & & $\checkmark$ & & & & \\
\hline Vital signs & & $\checkmark$ & $\checkmark$ & $\checkmark$ & $\checkmark$ & $\checkmark$ \\
\hline Height & & $\checkmark$ & $\checkmark$ & $\checkmark$ & $\checkmark$ & $\checkmark$ \\
\hline Weight & & 2 & $\checkmark$ & 2 & 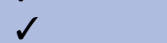 & 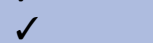 \\
\hline $\mathrm{BMI}$ & & 2 & 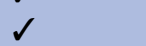 & 2 & 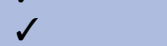 & 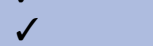 \\
\hline Parental height & & $\checkmark$ & & & & \\
\hline Target height & & 2 & & & & \\
\hline $\begin{array}{l}\text { Calculation of predictive definitive height value } \\
\text { (Tanner-Whitehouse method) }\end{array}$ & & $\checkmark$ & & & & \\
\hline Pubertal maturation & & $\checkmark$ & $\checkmark$ & $\checkmark$ & $\checkmark$ & $\checkmark$ \\
\hline SNAP-IV & & 2 & $\checkmark$ & 2 & & $\checkmark$ \\
\hline CGI-S & & $\checkmark$ & $\checkmark$ & $\checkmark$ & & $\checkmark$ \\
\hline CGI-I & & & 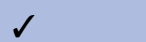 & 2 & & $\checkmark$ \\
\hline CGAS & & $\checkmark$ & $\checkmark$ & $\checkmark$ & & $\checkmark$ \\
\hline DCDQ'07 & & 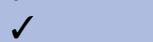 & & & & $\checkmark$ \\
\hline SCQ & & $\checkmark$ & & & & $\checkmark$ \\
\hline SDQ & & 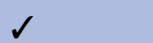 & $\checkmark$ & $\checkmark$ & & 2 \\
\hline AIMS & & $\checkmark$ & $\checkmark$ & $\checkmark$ & & $\checkmark$ \\
\hline $\mathrm{CSHQ}$ & & $\checkmark$ & 2 & 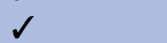 & & 2 \\
\hline MFQ-P (parent version) & & $\checkmark$ & $\checkmark$ & $\checkmark$ & & $\checkmark$ \\
\hline MFQ-C (self-report version) ages $\geq 8$ years & & 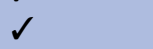 & $\checkmark$ & $\checkmark$ & & $\checkmark$ \\
\hline PLikS & & $\checkmark$ & $\checkmark$ & $\checkmark$ & & $\checkmark$ \\
\hline DAWBA Tics & & $\checkmark$ & $\checkmark$ & $\checkmark$ & & $\checkmark$ \\
\hline YGTSS & & $\checkmark$ & $\checkmark$ & $\checkmark$ & & $\checkmark$ \\
\hline $\begin{array}{l}\text { DAWBA rapidly changing mood (parent } \\
\text { version) }\end{array}$ & & $\checkmark$ & $\checkmark$ & $\checkmark$ & & $\checkmark$ \\
\hline DAWBA rapidly changing mood (child version) & & $\checkmark$ & $\checkmark$ & $\checkmark$ & & $\checkmark$ \\
\hline DAWBA awkward and troublesome behaviour & & 2 & $\checkmark$ & 2 & & $\checkmark$ \\
\hline C-SSRS (baseline) & & $\checkmark$ & & & & \\
\hline C-SSRS (since last seen) & & & $d$ & $\checkmark$ & & $\checkmark$ \\
\hline Substance use questionnaire & & $\checkmark$ & $\checkmark$ & $\checkmark$ & & $\checkmark$ \\
\hline
\end{tabular}

AIMS, Abnormal Involuntary Movement Scale; BMI, body mass index; CGAS, Children's Global Assessment; CGI, Clinical Global Impressions; CSHQ, Child's Sleep Habits Questionnaire; C-SSRS, Columbia-Suicide Severity Rating Scale; DAWBA, Development and Wellbeing Assessment; DCDQ'07, Developmental Coordination Disorder Questionnaire '07; MFQ, Mood and Feelings Questionnaire; PLikS, Psychosis Like Symptoms; SCQ, Social Communication Questionnaire; SDQ, Strength and Difficulties Questionnaire; SNAP-IV, Swanson Nolan and Pelham IV rating scale; YGTSS, Yale Global Tic Severity Scale.

subsequently be entered into an electronic version of the CRF (eCRF) at each site. The eCRF was developed by the Health Informatics Centre (HIC) at the University of Dundee ${ }^{56}$ using Openclinica open source software. $^{57}$

Primary outcome data entered into the database will be verified against source data in the paper CRFs. A proportion of secondary outcome data will also be verified depending on the resources available.

Analysis plan

Description at baseline

Characteristics of participants included in the study will be presented using the 'five number summary' 
(minimum, maximum, lower and upper quartiles and median) for the quantitative variables, and percentages for categorical variables. The whole sample and each of the three groups will be presented in this way. Traditional trivariate/bivariate comparisons will be carried out to compare the groups (eg, analysis of variance (ANOVA), $\chi^{2}$ tests or non-parametric tests, according to their conditions of validity). Graphical representations will be used to characterise distributions (histograms, density plots, box plots) or to explore patterns of association of covariates (multidimensional exploratory graphical methods). When participants change their status, their data will be censored for analyses.

\section{Longitudinal description}

The evolution of data with time will be graphically and numerically presented. This part is essential, in particular to design the mixed models used to analyse the primary end point (see below).

\section{Incidence rates and relative risk}

These will be estimated according to the number of participant-years available in the study at the time of analysis. For a given participant, only the first occurrence of a side effect will be considered. Incidence rates will be estimated in each of the three groups.

\section{Bivariate analysis}

The association with the primary and secondary end points will be statistically tested with all potential covariates of interest (including time on drug and dose and duration of treatment) using traditional procedures (eg, correlations, ANOVA, $\chi^{2}$ tests or non-parametric tests according to conditions of validity). These tests will be regarded as strictly exploratory.

\section{Analysis of primary end point}

The child's height velocity will be estimated from all available data using a simple linear regression of height with time (one linear regression for each participant). Child's height velocity and child's height velocity SDS will thus be available only for participants having at least two visits. The distribution of height velocity SDS will be carefully examined (density plot with standardised normal plot). If this distribution is normal, a mixed model for normal outcome will be used. The primary predictor variable will be 'group' (medicated ADHD, unmedicated ADHD, non-ADHD controls). The covariates will be:

1. Three propensity scores contrasting each of the three pairs of group categories (ie, medicated vs unmedicated, medicated vs non-ADHD, unmedicated vs non-ADHD). These propensity scores will be estimated from a logistic regression incorporating all available data (at the condition of convergence of the maximum likelihood estimator). A regression spline between height velocity SDS and each of the three logistic scores will help to determine how these propensity scores will be introduced in the model (linear, polynomial, deciles, etc). The propensity scores will be estimated after imputing missing data using a Gibbs sampler.

2. 'Family' as a random effect (to take into account the pairing of groups medicated ADHD and nonmedicated sibling).

3. 'Country'.

4. 'Duration of treatment'.

Additional adjustment for potential confounders, or adjustment by inclusion of variables (measured at baseline) that are considered essential (because of their clinical relevance, because of the bivariate analysis or because the propensity scores were unsuccessful in suppressing the imbalance between groups for a given covariate), may also be necessary.

No adjustment of $\mathrm{p}$ values for inclusion of multiple covariates will be carried out, since the primary hypothesis concerns the effect of the 'group' variable, and since in a pharmacovigilance study statistical power is at least as important as type one error.

The effect of the 'group' variable will be assessed globally, then with planned contrasts comparing medicated versus unmedicated, and medicated versus non-ADHD.

Missing data in adjustment covariates will be imputed using a Gibbs sampler (simple imputation because inferential statistics especially concern the variable 'group')

Regression diagnostics will be performed.

Interaction terms, for example, age and sex, will be tested one at a time to look for specific populations at risk.

If the height velocity SDS is not normally distributed, linearising transformations will be tried (log, box-cox, etc). If no transformation is possible, a bootstrap procedure will be used.

Finally, sensitivity analyses will be conducted to test the robustness of the results, for example, removal of patients who switch treatment and patients with concurrent psychotropic drugs.

\section{Ethics and dissemination}

The study will be conducted according to the principles of the Declaration of Helsinki ${ }^{58}$ and in accordance with the Research Governance Framework Scotland and other appropriate guidelines and regulations in each country. ${ }^{59}$ Since the study is purely observational, there are no anticipated extra risks to participants. Results will be disseminated through peer-reviewed publications and a lay summary of the results will be posted on the study website.

MPH is recommended as the first choice medication for ADHD and is the most frequently used in Europe. ${ }^{3}$ Despite the evidence of positive effects of stimulants on the core symptoms of ADHD supported by numerous studies ${ }^{20}{ }^{60}$ many unanswered questions remain about the underlying biological mechanism and the mediators 
and moderators of possible adverse effects as the ones emphasised by CHMP and objectives of this project.

At present, a guidelines group of the European Network for Hyperkinetic Disorders (EUNETHYDIS) recommends careful physical assessment of children and adolescents before and during chronic treatment with psychostimulants. ${ }^{61}$ With regard to the possible effects on growth, it is highly recommended to assess growth parameters before stimulant treatment with periodic monitoring through repeated measurements of weight and height and their changes over time (at least three or four times per year). Likewise, pretreatment checking and monitoring of pulse and blood pressure are also recommended with ADHD medication, with frequency of monitoring either three-monthly ${ }^{62}$ or six-monthly. ${ }^{3}$ Blood pressure recorded as a centile score allows appropriate referral to a paediatric hypertension expert when at least two consecutive recordings are above the 95th centile. When the pulse rate is consistently above 120 / min, a referral to a paediatric cardiologist is appropriate. According to the same guidelines, a careful monitoring of psychiatric and neurological potential adverse effects is also recommended.

In this context, the ADDUCE project, with a long follow-up period and a rigorous methodology, will provide important information about the safety of psychostimulant medications within the ADHD population, covering various aspects of potential adverse events in children and adolescents with a range of different ADHD symptoms. The project will also help in understanding and answering the present unsolved questions about underlying biological mechanisms including possible mediators, moderators and confounders such as clinical and demographic characteristics and medication factors (average daily dose, cumulative dosage of MPH, pretreatment history of medication, use of co-medication). We expect that ADDUCE will also have an impact on research in paediatric psychopharmacology by establishing a collaborative network of expert centres, and that the dissemination of results will lead to improved standards of care and management of ADHD through the development of guidelines for a comprehensive personalised monitoring of treatment.

\footnotetext{
Author affiliations

${ }^{1}$ Division of Neuroscience, School of Medicine, University of Dundee \& Tayside Clinical Trials Unit, University of Dundee, Dundee, UK ${ }^{2}$ Child and Adolescent Neuropsychiatry Unit, Department of Biomedical Science, University of Cagliari, Cagliari, Italy

${ }^{3}$ Vadaskert Child and Adolescent Psychiatric Hospital, Budapest, Hungary ${ }^{4}$ Department of Child \& Adolescent Psychiatry and Psychotherapy, Medical Faculty Mannheim, Central Institute of Mental Health, University of Heidelberg, Mannheim, Germany

${ }^{5}$ Cognition and Behavior, Department of Cognitive Neuroscience, Radboud University Medical Centre, Donders Institute for Brain, Karakter Child and Adolescent Psychiatry University Centre, Nijmegen, The Netherlands ${ }^{6}$ Univercity Paris-Sud, Univ. Paris-Descartes, AP-HP, INSERM U1178, Paris, France

${ }^{7}$ Faculty of Medicine \& Health Sciences, Institute of Mental Health, University of Nottingham, Nottingham, UK

${ }^{8}$ Academic Unit of Psychology, University of Southampton, Southampton, UK
}

${ }^{9}$ School of Pharmacy, University College Cork, Cork, Ireland

${ }^{10}$ Department of Paediatrics and Adolescents Medicine, University Hospital Erlangen, Erlangen, Germany

${ }^{11}$ Evelina Children's Hospital, St Thomas' Hospital, London, UK

${ }^{12} \mathrm{UK}$ and Department of Experimental Clinical \& Health Psychology, University of Southampton, Ghent University, Belgium

${ }^{13}$ UCL School of Pharmacy, 29-39 Brunswick Square, London, UK

${ }^{14}$ Division of Neuroscience, School of Medicine, University of Dundee,

Dundee, UK

Acknowledgements The authors wish to thank the children and adolescents who are taking part in the study, and their families. They also acknowledge the support of the Scottish Mental Health Research Network and the Mental Health Research Network.

Contributors SKI managed the study and wrote the manuscript. SC coordinated the Italian sites, ran the Italian substudy and helped write the manuscript. PG helped coordinate the project in Hungary and helped write the manuscript. $\mathrm{AH}$ coordinated the project in Mannheim and helped write the manuscript. TB, BF and ES-B were involved in the design of the study and commented on drafts of the manuscript. JB contributed to the conception and design of the study and commented on drafts of the manuscript. RWD managed study-related procedures in Germany and commented on drafts of the manuscript. CH, HK, EL and ER commented on the manuscript. SM commented on drafts of the manuscript. PN coordinated study-related procedures in Hungary and commented on drafts of the manuscript. AN contributed to the design of the study and reviewed the manuscript. IW was involved in the conception and design of the study and commented on drafts of the manuscript. AZ was involved in the design of the study, including the substudy on the Italian medicated cohort, and commented on drafts of the manuscript. DCC designed and led the study and commented on drafts of the manuscript.

Funding This project has received funding from the European Union's Seventh Framework Programme for research, technological development and demonstration under grant agreement no 324487.

Competing interests SKI is funded by the EU FP7 framework. SC has received conference attendance support from Shire. She has been involved in clinical trials conducted by Shire. She is participating in an EU-funded project. $\mathrm{AH}$ has received compensation for serving as consultant or speaker for, or the institution he works for has received research support or royalties, from the companies or organisations indicated below: E. Lilly, Shire, Janssen-Cilag, Otsuka, Sunovion, Takeda, Theravance, German Research Foundation (DFG), German Ministry of Education and Research (BMBF), European Union (EU FP7 programme). TB served in an advisory or consultancy role for Hexal Pharma, Lilly, Medice, Novartis, Otsuka, Oxford outcomes, PCM scientific, Shire and Viforpharma. He received conference attendance support and conference support or received speaker's fee from Lilly, Medice, Novartis and Shire. He is/has been involved in clinical trials conducted by Shire \& Viforpharma. The present work is unrelated to the above grants and relationships. JKB has, in the past 3 years, been a consultant to/member of the advisory board of/and/or speaker for Janssen Cilag BV, Eli Lilly, Bristol-Myer Squibb, Shering Plough, UCB, Shire, Novartis and Servier. He is neither an employee nor a stock shareholder of any of these companies. RWD has received compensation for serving as consultant or speaker for (or the institution he works for has received research support or royalties from) the companies or organisations indicated below: Boehringer Ingelheim, European Union (EU FP7 programme), Ferring, German Ministry of Education and Research (BMBF), German Research Foundation (DFG), German Ministry of Health/the German Regulatory Body (BfArM), Janssen-Cilag, E. Lilly, Otsuka, Servier, Shire, Sunovion, Takeda, Theravance, US National Institute of Mental Health (NIMH). BF has been consultant for E. Lilly, BMS, Servier, SANOFI, GSK, HRA, Roche, Boeringer Ingelheim, Bayer, Almirall, Allergan, Stallergene, Genzyme, Pierre Fabre, Astrazeneca, Novartis, Janssen, Astellas, Biotronik, Daiichi-Sankyo, Gilead, MSD, Lundbeck, Stallergene, Actelion, UCB, Otsuka, Grunenthal and ViiV. SM has, in the past 3 years, received fees for speaking from Shire. PN has, in the past 3 years, received investigator's fees for clinical trials from Otsuka, Shire and Servier, and conference support from Shire. ER has received speaker's fees from Shire but that is unrelated to this study. 
ES-B has, in the past 3 years, received: fees for speaking, consultancy, research funding and conference support from Shire Pharma; speaker fees from Janssen Cilag, Medice \& Qbtech; book royalties from OUP and Jessica Kingsley; consultancy fees from Neurotech solutions. IW received funding from the EU FP7 grant, Hong Kong Research Grant Council and Janssen Cilag for ADHD research. AZ has, in the past 3 years, been a consultant to/member of advisory board of/and/or speaker for Shire, Otsuka, Lundbeck and Takeda. He is neither an employee nor a stock shareholder of any of these companies. He has received research funding from the European Union (EU FP7) and the Sardinian Regional Health Secretary and royalties from Oxford Unversity Press and Giunti OS. DCC has, in the past 3 years, received research funding from Shire, been a consultant to/member of the advisory board of/and/or speaker for Janssen Cilag, Eli Lilly, Shire, Novartis, Medice and Lundbeck. He has received royalties from Oxford University Press.

Ethics approval East of Scotland Research Ethics Service (reference $11 / \mathrm{ES} / 0016)$

\section{Provenance and peer review Not commissioned; externally peer reviewed.}

Open Access This is an Open Access article distributed in accordance with the Creative Commons Attribution Non Commercial (CC BY-NC 4.0) license, which permits others to distribute, remix, adapt, build upon this work noncommercially, and license their derivative works on different terms, provided the original work is properly cited and the use is non-commercial. See: http:// creativecommons.org/licenses/by-nc/4.0/

\section{REFERENCES}

1. American Psychiatric Association. Diagnostic and Statistical Manual of Mental Disorders. Arlington, VA: American Psychiatric Association, 2013.

2. Polanczyk G, de Lima MS, Horta BL, et al. The worldwide prevalence of ADHD: a systematic review and metaregression analysis. Am J Psychiatry 2007;164:942-8.

3. Taylor E, Dopfner M, Sergeant J, et al. European clinical guidelines for hyperkinetic disorder-first upgrade. Eur Child Adolesc Psychiatry 2004;13(Suppl 1):17-30.

4. National Institute for Health and Clinical Excellence (NICE). Diagnosis and management of ADHD in children, young people and adults, 2013. National Clinical Practice Guideline Number 72. https://www.nice.org uk/guidance/cg72/.../adhd-full-guideline-241963165

5. Volkow ND, Wang GJ, Fowler JS, et al. Relationship between blockade of dopamine transporters by oral methylphenidate and the increases in extracellular dopamine: therapeutic implications. Synapse 2002;43:181-7.

6. Greenhill LL. Clinical effects of stimulant medications. In: Solanto MV, Arnsten AFT, Castellanos FX, eds. Stimulant drugs and ADHD. New York: Oxford University Press, 2001:31-71.

7. Care Commission. The safer management of controlled drugs. 2012 http://www.cqc.org.uk/sites/default/files/documents/cdar_2012.pdf

8. Schubert I, Köster I, Lehmkuhl G. The changing prevalence of attention-deficit/hyperactivity disorder and methylphenidate prescriptions: a study of data from a random sample of insurees of the AOK Health Insurance Company in the German State of Hesse, 2000-2007. Dtsch Arztebl Int 2010;107:615-21.

9. Janols LO, Liliemark J, Klintberg K, et al. Central stimulants in the treatment of attention-deficit hyperactivity disorder (ADHD) in children and adolescents. A naturalistic study of the prescription in Sweden, 1977-2007. Nord J Psychiatry 2009;63:508-16.

10. Gumy C, Huissoud T, Dubois-Arber F. Prevalence of methylphenidate prescription among school-aged children in a Swiss population: increase in the number of prescriptions in the Swiss Canton of Vaud, from 2002 to 2005, and changes in patient demographics. J Atten Disord 2010;14:267-72.

11. Criado-Alvarez JJ, Romo-Barrientos C. [Variability and tendencies in the consumption of methylphenidate in Spain. An estimation of the prevalence of attention deficit hyperactivity disorder]. Rev Neurol 2003;37:806-10.

12. Visser SN, Danielson ML, Bitsko RH, et al. Trends in the parent-report of health care provider-diagnosed and medicated attention-deficit/hyperactivity disorder: United States, 2003-2011. J Am Acad Child Adolesc Psychiatry 2014;53:34-46.e2.

13. Man KK, Ip P, Hsia Y, et al. ADHD drug prescribing trend is increasing among children and adolescents in Hong Kong. J Atten Disord 2014. doi: 1087054714536047

14. European Union. Community referral. 2007. http://www.ema.europa. eu/docs/en_GB/document library/Referrals document/ Methylphenidate_31/WC500011138.pdf
15. European Union. Understanding community referrals. 2013. http:// www.transcrip-partners.com/wp-content/uploads/2013/07/ Understanding-regulatory-referral-procedures-Differences-betweenArticle-30-and-Article-31-1.pdf

16. European Union. Referrals document. 2009. http://www.ema.europa. eu/docs/en_GB/document_library/Referrals_document/ Methylphenidate 31/WC500011125.pdf

17. European Union. 4th Call of the European Commission's Framework Programme (FP7). 2009. http://www.gmp-publishing.com/en/gmpnews/gmp-aktuell/emea-announcement-of-european-medicinesagency-priorities-for-adverse-drug-reaction-research.html

18. ADDUCE consortium. Attention Deficit Hyperactvity Drugs Use Chronic Effects. http://www.adhd-adduce.org/page/view/2/Home

19. Faraone SV, Biederman J, Morley CP, et al. Effect of stimulants on height and weight: a review of the literature. J Am Acad Child Adolesc Psychiatry 2008;47:994-1009.

20. Poulton A. Growth on stimulant medication; clarifying the confusion: a review. Arch Dis Child 2005;90:801-6.

21. Poulton AS, Melzer E, Tait PR, et al. Growth and pubertal development of adolescent boys on stimulant medication for attention deficit hyperactivity disorder. Med J Aust 2013;198:29-32.

22. Swanson J, Arnold LE, Kraemer $\mathrm{H}$, et al. Evidence, interpretation, and qualification from multiple reports of long-term outcomes in the Multimodal Treatment study of Children With ADHD (MTA): part I: executive summary. J Atten Disord 2008;12:4-14.

23. Swanson J, Arnold LE, Kraemer $\mathrm{H}$, et al. Evidence, interpretation, and qualification from multiple reports of long-term outcomes in the Multimodal Treatment study of children with ADHD (MTA): part II: supporting details. J Atten Disord 2008;12:15-43.

24. Iversen L. Neurotransmitter transporters and their impact on the development of psychopharmacology. Br J Pharmacol 2006;147: S82-8.

25. Vetter VL, Elia J, Erickson C, et al. Cardiovascular monitoring of children and adolescents with heart disease receiving medications for attention deficit/hyperactivity disorder [corrected]: a scientific statement from the American Heart Association Council on Cardiovascular Disease in the Young Congenital Cardiac Defects Committee and the Council on Cardiovascular Nursing. Circulation 2008;117:2407-23.

26. Howes OD, Kambeitz J, Kim E, et al. The nature of dopamine dysfunction in schizophrenia and what this means for treatment. Arch Gen Psychiatry 2012;69:776-86.

27. Bussing R, Fernandez M, Harwood M, et al. Parent and teacher SNAP-IV ratings of attention deficit hyperactivity disorder symptoms: psychometric properties and normative ratings from a school district sample. Assessment 2008;15:317-28.

28. Goodman R. Psychometric properties of the strengths and difficulties questionnaire. J Am Acad Child Adolesc Psychiatry 2001;40:1337-45.

29. Tanner JM, Whitehouse RH, Takaishi M. Standards from birth to maturity for height, weight, height velocity, and weight velocity: British children, 1965. I. Arch Dis Child 1966;41:454-71.

30. Tanner JM, Whitehouse RH, Takaishi M. Standards from birth to maturity for height, weight, height velocity, and weight velocity: British children, 1965. II. Arch Dis Child 1966:41:613-35.

31. Preuss U, Ralston SJ, Baldursson G, et al., ADORE Study Group. Study design, baseline patient characteristics and intervention in a cross-cultural framework: results from the ADORE study. Eur Child Adolesc Psychiatry 2006;15(Suppl 1):14-14.

32. Scottish Children's Research Network. Standard Operating Procedure. http://www.scotcrn.org/professional/network-sops/

33. Marshall WA, Tanner JM. Variations in the pattern of pubertal changes in boys. Arch Dis Child 1970;45:13-23.

34. Marshall WA, Tanner JM. Variations in pattern of pubertal changes in girls. Arch Dis Child 1969;44:291-303.

35. Guy W. ECDEU assessment manual for psychopharmacology. Rockville, MD, USA: Department of Health, Education, and Welfare, 1976.

36. Shaffer D, Gould MS, Brasic J, et al. A children's global assessment scale (CGAS). Arch Gen Psychiatry 1983;40:1228-31.

37. Wilson BN, Crawford SG, Green D, et al. Psychometric properties of the revised Developmental Coordination Disorder Questionnaire. Phys Occup Ther Pediatr 2009;29:182-202.

38. Berument SK, Rutter M, Lord C, et al. Autism screening questionnaire: diagnostic validity. Br J Psychiatry 1999;175:444-51.

39. Angold A, Costello EJ, Messer SC, et al. The development of a short questionnaire for use in epidemiological studies of depression in children and adolescents. Int $J$ Methods Psychiatr Res 1995;5:237-49.

40. Zammit S, Horwood J, Thompson A, et al. Investigating if psychosis-like symptoms (PLIKS) are associated with family history 
of schizophrenia or paternal age in the ALSPAC birth cohort. Schizophr Res 2008;104:279-86.

41. Goodman R, Ford T, Richards $\mathrm{H}$, et al. The Development and Well-Being Assessment: description and initial validation of an integrated assessment of child and adolescent psychopathology. $J$ Child Psychol Psychiatry 2000;41:645-55.

42. Leckman JF, Riddle MA, Hardin MT, et al. The Yale Global Tic Severity Scale: initial testing of a clinician-rated scale of tic severity. J Am Acad Child Adolesc Psychiatry 1989;28: $566-73$

43. Molina BS, Pelham WE Jr. Childhood predictors of adolescent substance use in a longitudinal study of children with ADHD. J Abnorm Psychol 2003;112:497-507.

44. Munetz MR, Benjamin S. How to examine patients using the Abnormal Involuntary Movement Scale. Hosp Community Psychiatry 1988;39:1172-7.

45. Owens JA, Spirito A, McGuinn M. The Children's Sleep Habits Questionnaire (CSHQ): psychometric properties of a survey instrument for school-aged children. Sleep 2000;23:1043-51.

46. National High Blood Pressure Education Program Working Group on High Blood Pressure in Children and Adolescents. The fourth report on the diagnosis, evaluation, and treatment of high blood pressure in children and adolescents. Pediatrics 2004:114(2 Suppl 4th Report):555-76.

47. Tayside Clinical Trials Unit. Tayside Clinical Trials Unit. 2014. http:// www.tasc-research.org.uk/research/tayside-clinical-trials-unit

48. International conference on harmonisation of technical requirements for registration of pharmaceuticals for human use (ICH). Good Clinical Practice. 1996. http://www.ich.org/products/ guidelines/efficacy/efficacy-single/article/good-clinical-practice. html

49. Pliszka SR, Matthews TL, Braslow KJ, et al. Comparative effects of methylphenidate and mixed salts amphetamine on height and weight in children with attention-deficit/ hyperactivity disorder. J Am Acad Child Adolesc Psychiatry 2006;45:520-6.

50. Charach A, Figueroa M, Chen S, et al. Stimulant treatment over 5 years: effects on growth. J Am Acad Child Adolesc Psychiatry 2006;45:415-21.
51. Zhang $\mathrm{H}$, Du M, Zhuang S. Impact of long-term treatment of methylphenidate on height and weight of school age children with ADHD. Neuropediatrics 2010;41:55-9.

52. Klein RG, Landa B, Mattes JA, et al. Methylphenidate and growth in hyperactive children. A controlled withdrawal study. Arch Gen Psychiatry 1988;45:1127-30.

53. Hechtman L, Weiss G, Perlman T. Young adult outcome of hyperactive children who received long-term stimulant treatment. J Am Acad Child Psychiatry 1984;23:261-9.

54. Tanner JM, Whitehouse RH, Marshall WA, et al. Prediction of adult height from height, bone age, and occurrence of menarche, at ages 4 to 16 with allowance for midparent height. Arch Dis Child 1975;50:14-26.

55. Pyle SI, Waterhouse AM, Greulich WW. Attributes of the radiographic standard of reference for the National Health Examination Survey. Am J Phys Anthropol 1971;35:331-7.

56. Health Informatics Centre. Health Informatics Centre Services. http:// medicine.dundee.ac.uk/hic.

57. OpenClinica. OpenClinica Open Source for Clinical Research. https://openclinica.com/

58. World Medical Association. Declaration of Helsinki-ethical principles for medical research involving human subjects. www.wma. net/en/30publications/10policies/b3/17c.pdf

59. The Scottish Government. Research Governance. http://www.gov. scot/Topics/Research/by-topic/health-community-care/ chief-scientist-office/6864/6933

60. Barkley RA, Macias M. Attention deficit hyperactivity disorder. In: David R, ed. Child and adolescent neurology. 3rd edn. New York: Blackwell, 2005.

61. Graham J, Banaschewski T, Buitelaar J, et al. European guidelines on managing adverse effects of medication for ADHD. Eur Child Adolesc Psychiatry 2011;20:17-37.

62. Kendall T, Taylor E, Perez A, et al. Diagnosis and management of attention-deficit/hyperactivity disorder in children, young people, and adults: summary of NICE guidance. BMJ 2008;337:a1239.

63. Posner K, Brown GK, Stanley B, et al. The Columbia-Suicide Severity Rating Scale: initial validity and internal consistency findings from three multisite studies with adolescents and adults. Am J Psychiatry 2011;168:1266-77. 